Others were created with input from potential customers or partners, but many aspects of their design, production, and marketing would have benefited had third parties taken over these roles.

Discussion By better understanding the nature of an innovation and by framing that innovation in a business-rather than a laboratory-context, research organisations are more likely to successfully commercialise their technologies. By establishing stronger positions within industry value chains, research organisations are able to form partnerships and better leverage their own core competencies.

\section{$1675 c$ A HANDY DECISION AID FOR TRANSLATING RESEARCH FINDINGS INTO A VISUAL FORMAT TO AID DISSEMINATION}

Jani Routsalainen, Jos Verbeck. Cochrane Work, Finnish Institute of Occupational Health, Kuopio, Finland

\subsection{6/oemed-2018-ICOHabstracts.191}

Introduction Cochrane is a global scientific network that produces evidence on the effectiveness of all manner of interventions to improve health. The organisation also promotes the use of this evidence in decision making both at the personal as well as the population level. Over the past few years Cochrane has developed a Knowledge Translation (KT) strategy to better ensure that the evidence it produces has real effects in real life by making people healthier and safer. One exciting and constantly growing area in KT is visualisation because pictures grab people's attention and they are easy to share via social media.

Methods Using an open, iterative, trial-and-error approach, we have developed a decision tree (a particular kind of flowchart) to help anyone interested in turning Cochrane review results - published as text, numbers and statistical graphs - into more easily understandable visual formats.

Result The decision tree will be publically available in all its development versions via www.visuallycochrane.net.

Discussion Visualisations of Cochrane review results can range from the relatively simple form of adding a photograph to a tweet at one end of the spectrum to the production of sizeable infographics or even videos at the other. There are factors inherent to the obtained review results, such as direction and magnitude of effect and the quality of the evidence, as well the general context within which they apply that can be operationalized into a rough algorithm. Even though the tool is developed especially with Cochrane reviews in mind, there is no reason to assume it would not apply equally to other kinds of research findings and their dissemination within the OHS realm. The tool will be presented in Dublin in its current form to elicit feedback to develop it further.

\section{5d KNOWLEDGE TRANSFER AND EXCHANGE IN WORK AND HEALTH: REACHING WORKPLACE AUDIENCES}

\footnotetext{
1,2D Van Eerd. 'Institute for Work and Health, Toronto, Canada; ${ }^{2}$ University of Waterloo, Waterloo, Canada
}

\subsection{6/oemed-2018-ICOHabstracts. 192}

Introduction Workplace injury and illness can be burdensome for individual workers, workplaces, medical systems, insurance systems and society as a whole. The notion of research to practice is important in work and health research. Konwledge transfer and exchange (KTE) is the practice of generation synthesis and dissemination of research. The objective of this presentation is to synthesise the literature describing KTE activities relevant to workplace health and safety programs and interventions.

Methods A comprehensive review of the literature was completed. Search strategies developed using terms for knowledge transfer and occupational health and safety were run in six electronic databases. (Medline, Embase, Eric, Social sciences, Web of Science, and Business Source Premier). References of relevant documents and hand-searching complimented the search. Documents that described a KTE approach for workplaces were reviewed. KTE approach data were extracted and synthesised according to a framework by Lavis (2003) (What, To whom, By Whom, How, and With what effect) as well as conceptual guidance.

Results Literature searchers revealed 34 documents that described 23 different KTE approaches designed to reach workplaces. The KTE approaches addressed workplace and intermediary audiences. KTE methods and outcomes varied greatly according to the context. However, there were common elements including targeting workers as a key audience involving researchers in dissemination and using multi-dissemination methods. Dissemination method consistently included direct interaction but also often featured printed materials. Many KTE approaches were guided by conceptual frameworks. However, no single conceptual framework was predominant.

Conclusion Common elements related to audience, activities and impact were found in the literature that can help to guide future KTE approaches. Including workers as an audience and researchers as disseminators in a multi-faceted approach along with in-person meetings and printed material are important aspects of KTE for work and health. Conceptual guidance was content dependent.

\section{$1675 \mathrm{e}$ THE NEW DANISH FRAMEWORK FOR KNOWLEDGE TRANSLATION AND EXCHANGE (KTE)}

I Schaumburg. National Research Centre for the Working Environment, Copenhagen, Denmark

\subsection{6/oemed-2018-ICOHabstracts.193}

Introduction The NRCWE's is a government research institute. This makes relevance and user-orientation basic terms when it comes to the institute's working environment research and research dissemination. However, our experiences shows that there may be a gap between research results and the workplaces' ability to put research into practice. For different reasons, research results are not always put into practice, and the causes to the problem cannot be limited to be a communication problem only. The NRCWE is thus conducting research with the purpose to increase our knowledge of implementation possibilities and to develop new operational methods. Systematic involvement of stakeholders and target groups during the whole research process and development of collaboration, networks and partnerships in dissemination of research are central elements. The NRCWE's ambition is to develop and implement Knowledge Transfer and Exchange (KTE) in its overall strategy 2018-2021. 
Methods The NRCWE has been working with the development and implementation of a relevant KTE-strategy on several levels:

a. For the entire research center

b. In the different research areas

c. In specific research projects

d. In the dissemination of research.

Results The aim is not only to increase the use of research results at the workplaces but also to strengthen the Danish Working Environment Authority, The Ministry of Employment's, the social partners and occupational health professional's use of research-based knowledge.

Conclusion Experiences and preliminary results from projects within different research areas will be presented iincluding what the new strategy means for the communication of research results.

\section{IMPROVING PUBLIC CORPORATE REPORTING ON OCCUPATIONAL HEALTH}

Bastian Buck*. GRI, Amsterdam, The Netherlands

\subsection{6/oemed-2018-ICOHabstracts. 194}

Aim of special session Thousands of companies globally report publicly on their occupational health programs and impacts. This information is used by a variety of stakeholders, such as investors, to inform decision making about companies. The availability of this information is, however, not yet widespread, and there are challenges with the quality and comparability of the data. A number of efforts are underway to improve and standardise this information. This session offers to learn from key organisations and experts in the field about latest developments on what is expected from companies regarding occupational health measurements and public disclosure. This session will also unveil the updates to the GRI Occupational Health and Safety reporting standard, which will outline minimum transparency expectations for companies globally around occupational health - including basic data on work-related illnesses, the management of health hazards, and the use of occupational health services and worker health promotion programs.

${ }^{1}$ Ms. Nancy J. Leppink, ${ }^{2}$ Ms. Laura Espinach, ${ }^{3}$ Mr. William G. Perry, ${ }^{4}$ Dr. Herbert J. Schilthuis

${ }^{1}$ International Labour Organisation, Geneva, Switzerland

${ }^{2}$ GRI, Amsterdam, The Netherlands

${ }^{3}$ U.S. Occupational Safety and Health Administration, Washington, DC, USA

${ }^{4}$ Heineken International, Amsterdam, The Netherlands

\section{4a THE NEED FOR RELIABLE DATA AND ROBUST INDICATORS TO DRIVE IMPROVEMENTS IN OSH PERFORMANCE}

NJ Leppink. International Labour Organisation, Geneva, Switzerland

10.1136/oemed-2018-ICOHabstracts. 195

International Labour standards promulgated by the International Labour Organisation have long called for ILO constituents to establish and support notification and recording systems for the collection of reliable data on work-related fatalities, injuries and diseases. The ILO has developed guidance and set out good practices in response to well document challenges constituents face when working to establishing effective notification and recording systems. These challenges are both technical and behavioural in nature. The United Nations Sustainable Development Goals, which require countries to report the frequency rates of fatal and non-fatal occupational injuries, by sex and migrant status has put the spotlight on the reliability of the data countries are reporting and the need for countries to improve notification and reporting systems before that indicator is a true measure of $\mathrm{OSH}$ performance. For this indicator to be relevant it should be accompanied by a means for measuring the capacity of countries' notification system to collect reliable and comparable data. Frequency rates of fatal and non-fatal injuries are lagging indicators and should be coupled with leading indicators that drive behaviours that correlate with improvements in $\mathrm{OSH}$ performance. Leading indicators need to be supported by research and have applicability to variety of contexts and the future of work. Leading indicators can be more readily aligned with positive incentives, such as improved productivity and competitiveness. Leading indicators may also be more effective in addressing occupational disease. Leading indicators need to be developed through a collaborative and consultative process engaging representatives of governments, employers, workers and the public to ensure their viability and acceptance.

\section{4b NEW STANDARD ON OCCUPATIONAL HEALTH AND SAFETY REPORTING}

L Espinach. GRI, Amsterdam, The Netherlands

10.1136/oemed-2018-ICOHabstracts.196

The GRI Sustainability Reporting Standards are used by more than 4000 organisations in over 90 countries to report on their economic, environmental and social impacts - including occupational health and safety (OHS) impacts. The GRI Standards are referenced in policy and regulation in more than 50 countries, and by nearly 40 stock exchanges worldwide. They are issued by the Global Sustainability Standards Board (GSSB), GRI's independent standard-setting body, and developed following a thorough Due Process Protocol, which ensures a transparent process and provides many opportunities for input from diverse stakeholders. GRI is reviewing its OHS reporting standard to align it with internationally-agreed best practice and recent developments in OHS management and reporting practice. The project addresses important topics such as the reporting of occupational illnesses, occupational health services, and worker health promotion, and will include a combination of leading and lagging indicators, as well as management approach disclosures. A multi-stakeholder expert Working Group is revising the content, and includes leading experts from the ILO, the Centre for Safety and Health Sustainability, IOSH, U.S. OSHA, as well as leading multinationals, among many others. This process will deliver a set of best practice metrics for organisations around the world to report on their OSH impacts in a standardised way. Ultimately, the transparency created by such a standard is intended to lead to positive change, thus contributing to sustainable development. The final standard is expected to be published during Q2 2018, the details of which will be unveiled at ICOH 2018. 